\title{
Uncertainties in monsoon precipitation projections over China: results from two high-resolution RCM simulations
}

\author{
Xuejie Gao ${ }^{1}$, Ying $\mathrm{Shi}^{1, *}{ }^{1,}$ Dongfeng Zhang ${ }^{1,2}$, Jia $\mathrm{Wu}^{1}$, Filippo Giorgi ${ }^{3}$, Zhenming $\mathrm{Ji}^{1}$, \\ Yongguang Wang ${ }^{1}$
}

\author{
${ }^{1}$ National Climate Center, China Meteorological Administration, Beijing 100081, China \\ ${ }^{2}$ Shanxi Climate Center, Taiyuan 030006, China \\ ${ }^{3}$ Abdus Salam International Centre for Theoretical Physics, 34100 Trieste, Italy
}

\begin{abstract}
A high-resolution climate change simulation at a grid spacing of $25 \mathrm{~km}$ was conducted over East Asia with the Abdus Salam International Centre for Theoretical Physics' (ICTP) regional climate model RegCM3, for the period 1951-2100. The model is driven at the lateral boundaries by the global model CCSR/NIES/FRCGC MIROC3.2_hires. Two time slices, 19611990 for present-day and 2071-2100 for future climate conditions were analyzed and compared with a previous high-resolution simulation of RegCM3 driven by the NASA/NCAR global model FvGCM. The focus of the present paper is on mean temperature and precipitation and their changes during the monsoon season (May-September). Overall, for present-day conditions, the regional model improves the simulation of both temperature and precipitation patterns compared to the driving global climate models, with greater agreement between the RegCM3 simulations than with the corresponding driving models. When driven by the 2 global models, RegCM3 simulates a consistent precipitation change pattern over western China, characterized by an increase over the northwest and a decrease over the Tibetan Plateau and Southwest China. These latter precipitation decreases have opposite signs compared those from the driving global models, and the causes of these differences (mostly associated with the different topographic representations) are discussed in the paper. This implies that over these regions the internal model physics and processes can be dominant factors. On the other hand, warming patterns are essentially driven by the large-scale boundary forcing. Our results show that precipitation change projections by current global models need to be considered cautiously and that the use of nested regional models adds an element of uncertainty which needs to be properly characterized.
\end{abstract}

KEY WORDS: Climate change $\cdot$ Regional climate model $\cdot$ Climate projections $\cdot$ Precipitation Uncertainty $\cdot$ Monsoon

Resale or republication not permitted without written consent of the publisher

\section{INTRODUCTION}

Recent decades have shown significant changes in observed precipitation over eastern China (one of the most populated areas of the world) known as the 'southern flood and northern drought'. This term describes an observed decrease of precipitation over North China and an increase over South China during the last decades (Wang 2001, Zhai et al. 2005, Zhou et al. 2008, 2009). South China, usually defined as the area south of the Yangtze River Basin (see Fig. 1c), is generally wet, with annual mean precipitation ranging from 1000 to $>1500 \mathrm{~mm}$. The observed increase in precipitation there is mostly associated with an increase of high-intensity precipitation events resulting in more frequent flood episodes (Zhai et al. 2005). 
Meanwhile, North China (north of the Huai River, which is located half way between the Yangtze and Yellow Rivers) is the transition zone from the humid climate of South China to the semi-arid climate of Inner-Mongolia, with annual precipitation decreasing from 800 to $<400 \mathrm{~mm}$. This is a region susceptible to drought, and the decrease in precipitation observed during the past decades has led to a worsening of these drought conditions. The possible persistence/intensification or the reverse of this 'southern flood and northern drought' pattern under global warming is a hot topic in China, and it is critical for the assessment of potential climate change impacts and the selection of corresponding adaptation measures in the country.

Monsoon precipitation (occurring mainly from May to September, MJJAS) accounts for $60-85 \%$ of the annual total precipitation over China. As the primary tool used for climate change projections, most of the atmospheric-ocean coupled general circulation models (AOGCMs) project a broad increase of monsoon precipitation over China (e.g. Giorgi et al. 2001, Giorgi \& Bi 2005, Christensen et al. 2007, Xu et al. 2009a). However, due to their coarse resolution, AOGCMs tend to exhibit a poor performance in describing the present-day monsoon climate of the region (e.g. Zhou \& Li 2002, Xu et al. 2010). Previous studies have shown that regional climate models (RCMs) can improve the simulation of East Asia monsoon climate (e.g. Gao et al. 2001, 2006, Yu et al. 2010). Furthermore, when used for climate change projections, RCMs not only can introduce finer scale topographically induced structures in the climate change signal, but can also simulate some significantly different regional scale patterns of change compared to the driving GCMs (e.g. Hirakuchi \& Giorgi 1995, Kato et al. 2001, Gao et al. 2008).

Gao et al. (2008) reported a high-resolution $(20 \mathrm{~km}$ grid spacing) multi-decadal RCM simulation over East Asia driven by the NASA/NCAR FvGCM global model run at $1^{\circ} \times 1.25^{\circ}$ (latitude-longitude) resolution. They analyzed monsoon precipitation (MJJAS) changes and found that, while the driving GCM simulated a predominant increase of precipitation over East Asia in agreement with most other GCMs, the nested RCM showed extended areas of decrease over the region. The causes of these differences were explained in terms of the different topographical forcings on circulation and moisture flux in the 2 models. A similar decrease of precipitation was also projected by some high-resolution GCM simulations, for example the atmospheric GCM time slice experiments (1980-2000, 2080-2100) conducted with the T319 $(\sim 40 \mathrm{~km})$ version of ECHAM5 by Feng et al. (2011).
Recently, a new set of climate change experiments for the period 1951-2100 at $25 \mathrm{~km}$ grid spacing were completed with the same RCM used in Gao et al. (2008) but driven by a different GCM, the CCSR/ NIES/FRCGC MIROC3.2_hires (K-1 Model Developers 2004). This allows a comparison with the results of Gao et al. (2008) which might yield relevant indications on the uncertainties related to monsoon precipitation projections over East Asia. In the current paper we thus present an analysis of projected changes in MJJAS precipitation for this new regional climate change experiment and compare it with previous analogous projections, focusing on mean climate changes and on differences between the RCM and driving GCM signals.

The paper is organized as follows. A short description of the model and simulation design is provided in Section 2. This is followed by a basic validation of the model performance in Section 3. The projected changes by the driving GCM and nested RCM are then compared and discussed in Section 4, and Section 5 presents our summary and conclusions.

\section{MODEL AND SIMULATIONS}

The RCM employed in our simulations, as well as in those of Gao et al. (2008), is the Abdus Salam International Centre for Theoretical Physics (ICTP) RegCM Version 3. It is based on the model of Giorgi et al. $(1993 a, b)$ with the upgrades described by Pal et al. (2007). In Gao et al. (2008), RegCM3 was driven by the climate change experiments conducted by Coppola et al. (2005) using the NASA/NCAR global model FvGCM/CCM3 (simulation hereafter referred to as FdR). Two time slices at $20 \mathrm{~km}$ grid spacing were conducted in FdR, 1961-1990 for present-day and 2071-2100 for future climate (plus 2 yr of spin-up time for each period) both under the IPCC SRES A2 emission scenario (IPCC 2000). More details on FdR can be found in Gao et al. (2008).

In the present simulations, RegCM3 is driven at the lateral boundaries by the AOGCM of CCSR/NIES/ FRCGC MIROC3.2_hires (hereafter referred to as MIROC; K-1 Model Developers 2004) and is run at $25 \mathrm{~km}$ grid spacing (simulation hereafter referred to as MdR). The MIROC was selected among the CMIP3 (Phase 3 of the Coupled Model Intercomparison Project) models because of its high resolution (T106, equivalent to $\sim 125 \mathrm{~km}$ ), its good performance in reproducing present-day climatology over China (Xu et al. 2007) and the availability of 6-hourly data to drive the RegCM3. MIROC had been used by 
Lenderink \& van Meijgaard (2010) to drive a different RCM over Europe. The simulation period of MdR is 1951-2100 plus 3 yr of spin-up time, with observed $\mathrm{CO}_{2}$ concentrations before and SRES A1B scenario concentrations (IPCC 2000) after 2000. The MIROC is at the high end of the CMIP3 models in terms of climate sensitivity (Randall et al. 2007); therefore, FdR and MdR can be roughly compared to each other even though MdR is using a scenario with lower $\mathrm{CO}_{2}$ concentrations. Note that FdR and MdR are the only 2 multi-decadal $\sim 20-25 \mathrm{~km}$ resolution RCM climate change simulations that have been completed over East Asia so far.

The RegCM3 uses the same model configuration in the 2 studies, except for the slight difference in resolution (20 vs. $25 \mathrm{~km}$ ). The model physics includes surface processes carried out with the biosphere-atmosphere transfer scheme (BATS; Dickinson et al. 1993), planetary boundary layer computations employing the non-local formulation of Holtslag et al. (1990), resolvable scale precipitation represented via the scheme of Pal et al. (2000), convective precipitation represented using the mass flux scheme of Grell (1993), and the atmospheric radiative transfer computed using the radiation package from the NCAR community climate model CCM3 (Kiehl et al. 1996). The RegCM3 also uses a similar domain in FdR and MdR which encompasses all of continental China and its adjacent areas. The topographical fields of FvGCM, MIROC, and RegCM3 in MdR are presented in Fig. 1a-c, respectively. The better definition of topography and coastlines in MdR compared to the 2 GCMs is evident from these figures.

From the simulation of a total of $150 \mathrm{yr}$, the common periods of 1961-1990 for present-day and 20712100 for future conditions are selected for analysis, in order to facilitate the comparison of the 2 simulations. The temperature observation dataset developed by $\mathrm{Xu}$ et al. (2009b) and the precipitation dataset by Xie et al. (2007), along with the CRU dataset (Mitchell \& Jones 2005) used when the former did not have available data (outside China for temperature, and outside China before 1978 and west of $65.25^{\circ} \mathrm{E}$ for precipitation), are employed to validate model performance. All the datasets have a resolution of $0.5^{\circ}$ latitude by $0.5^{\circ}$ longitude.

To facilitate the comparisons across datasets, the FvGCM, MIROC and FdR outputs, as well as the observational data, are interpolated bilinearly to the MdR grids. However, all datasets are kept at their original spatial resolution in order to identify possible added value by the increased horizontal resolution of the RCMs.

\section{a) FvGCM}

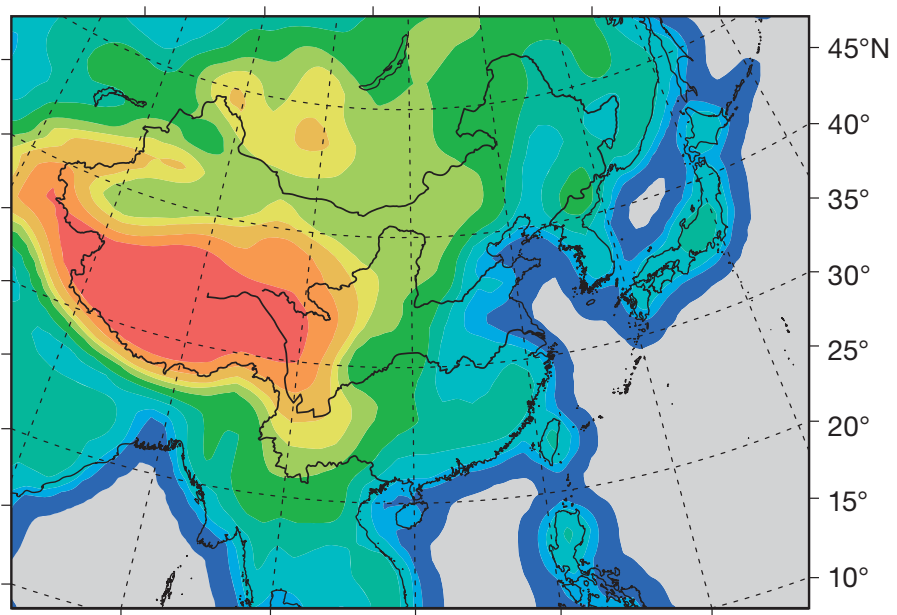

b) MIROC

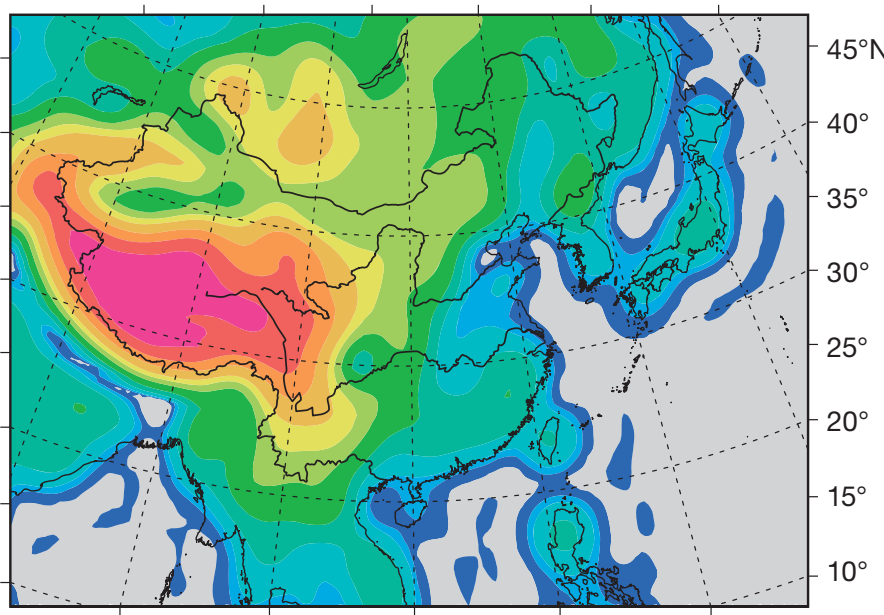

c) MdR

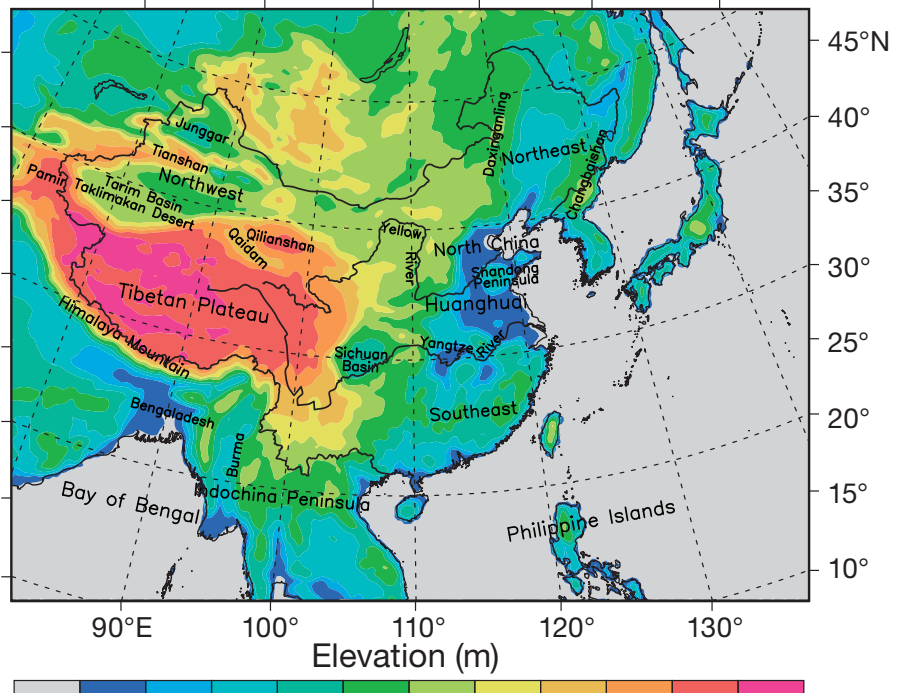

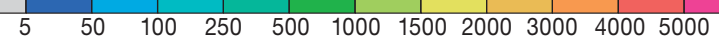

Fig. 1. Topography (m) of (a) FvGCM, (b) MIROC and (c) RegCM3 (with its domain) in MdR 


\section{VALIDATION OF PRESENT-DAY SIMULATIONS}

\subsection{Mean surface air temperature}

Firstly, we validate the simulated (both global models and RegCM3) mean temperature during the monsoon season (MJJAS) against the observations for the period 1961-1990 (Fig. 2a-e).

Interestingly, FvGCM and MIROC have temperature biases with more-or-less opposite patterns (Fig. 2b,d). In the former, the dominant bias is negative, except for the Tibetan Plateau region, while in the latter we find a dominant warm bias, except over Tibet. In both models, the magnitude of the bias varies in the range of -5 to $5^{\circ} \mathrm{C}$, with large areas where the bias is between -2 and $2^{\circ} \mathrm{C}$. The RegCM inherits some of these biases, but also shows different patterns from the driving GCMs. For example, the large warm bias in MdR over the northwestern areas of the domain is clearly inherited from the MIROC run. Similarly, the cold bias over the Indian and Indochina Peninsulas in FdR is seemingly inherited from, and in fact even magnified by, the FvGCM. Similarly, the regional model shows biases over the Tibetan Plateau that are consistent with the driving GCM run. On the other hand, over extended areas of eastern and northern China, the biases in the regional and driving global models are quite different. This indicates that, although the driving GCM has a strong influence on the bias, particularly in the regions close to the model boundaries, in the interior of the domain the model internal processes play a greater role. We also note that, in general, the magnitude of the bias in the regional model lies in the same range as in the driving GCMs.

For a more quantitative evaluation of the model performance, Table 1 provides values of the spatial correlation coefficients (CORs) and standard departures (STDs) between observations and simulations, and across simulations, for mean temperature, as done by Zhou \& Qian (1995) and Gao et al. (2008). COR and STD are defined as:

Table 1. Spatial correlation coefficients (CORs) / standard departures (STDs) $\left({ }^{\circ} \mathrm{C}\right)$ between observed and simulated surface air temperature, and across the model simulations over the model domain

\begin{tabular}{|lccccc|}
\hline & Observation & FvGCM & MIROC & FdR & MdR \\
\hline Observation & - & $0.955 / 2.4$ & $0.930 / 3.1$ & $0.972 / 1.8$ & $0.958 / 2.3$ \\
FvGCM & $0.955 / 2.4$ & - & $0.949 / 3.1$ & $0.944 / 2.4$ & $0.914 / 3.4$ \\
MIROC & $0.930 / 3.1$ & $0.949 / 3.1$ & - & $0.938 / 2.9$ & $0.948 / 2.6$ \\
FdR & $0.972 / 1.8$ & $0.944 / 2.4$ & $0.938 / 2.9$ & - & $0.973 / 2.0$ \\
MdR & $0.958 / 2.3$ & $0.914 / 3.4$ & $0.948 / 2.6$ & $0.973 / 2.0$ & - \\
\hline
\end{tabular}

$$
\begin{gathered}
\mathrm{COR}=\frac{\sum_{i=1}^{N}\left(x_{i f d 1}-\overline{x_{i f d 1}}\right)\left(x_{i f d 2}-\overline{x_{i f d 2}}\right)}{\sqrt{\sum_{i=1}^{N}\left(x_{i f d 1}-\overline{x_{i f d 1}}\right)^{2} \sum_{i=1}^{N}\left(x_{i f d 2}-\overline{x_{i f d} 2}\right)^{2}}} \\
\mathrm{STD}=\sqrt{\frac{\sum_{i=1}^{N}\left[\left(x_{i f d 1}-x_{i f d 2}\right)\right]^{2}}{N}}
\end{gathered}
$$

where $x_{i f d 1}\left(x_{i f d 2}\right)$ is the value of field1 (field2) at each grid point, $\overline{x_{\text {ifd } 1}}\left(\overline{x_{\text {ifd }}}\right)$ is the corresponding mean including all grid points, and $N$ is the total number of grid points.

We find that, compared to the driving GCMs, the regional model shows higher correlation and lower STD in both simulations, thereby indicating an overall improvement in the regional model skill compared to that of the global model. We also find that the correlation patterns (and STD) between the 2 regional model simulations are higher (lower) than between the regional and corresponding driving global models, again an indication that the internal model processes are important, if not dominant, in determining the performance of the regional model. On the other hand, we also find that in general all correlation patterns in Table 1 are high and the STD is roughly comparable across models and in the range of $2-3^{\circ} \mathrm{C}$.

\subsection{Mean precipitation}

Mean monsoon precipitation (MJJAS) in the observations and model simulations (both global models and RegCM3) for the period 1961-1990 is presented in Fig. 3a-e, respectively, while Fig. $4 a-d$ shows the corresponding biases. Compared to the observations (Fig. 3a), the main discrepancy found in the FvGCM simulation (Figs. 3b \& 4a) is the high precipitation center located at the eastern edge of the Tibetan Plateau (i.e. the area in the red boxes). This is a common feature of coarse-resolution GCMs (e.g. Xu et al. 2010) and can also be found in the MIROC simulation, although to a lesser extent (Fig. 3d). It is noted that this bias is much larger in the coarser resolution version of the MIROC (MIROC3.2 medres with a horizontal resolution of T42, figure not shown for brevity), illustrating the improvement of monsoon simulation by increasing horizontal resolution.

Another discrepancy between the GCMs and observations is the overes- 
a) CN05

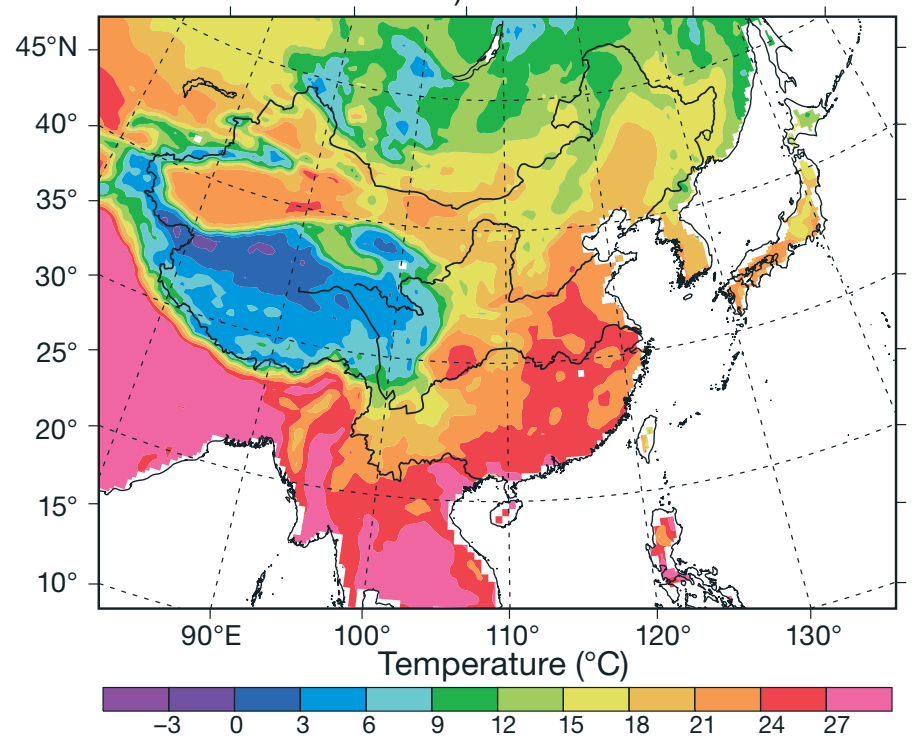

b) FvGCM

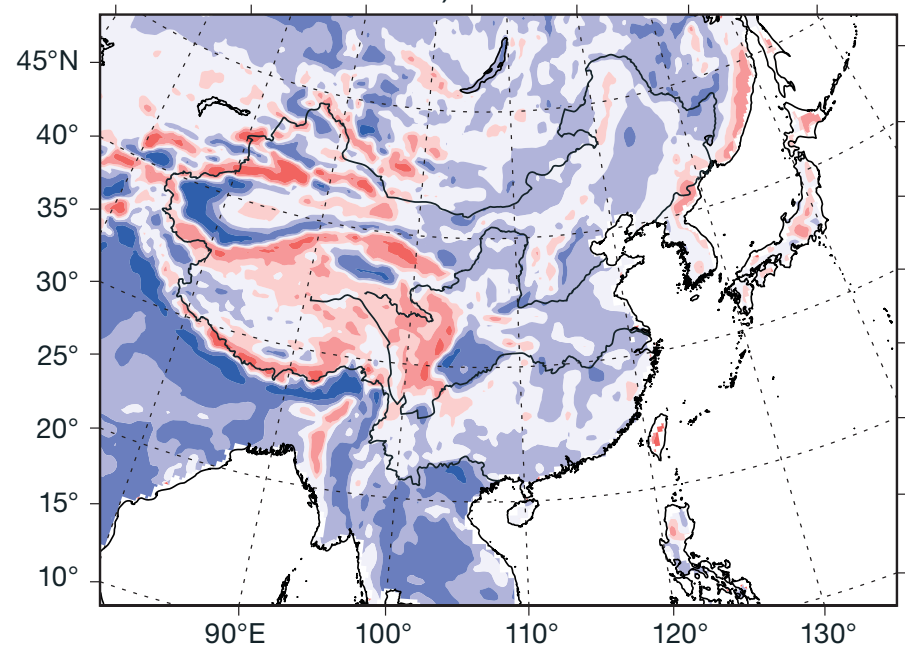

d) MIROC

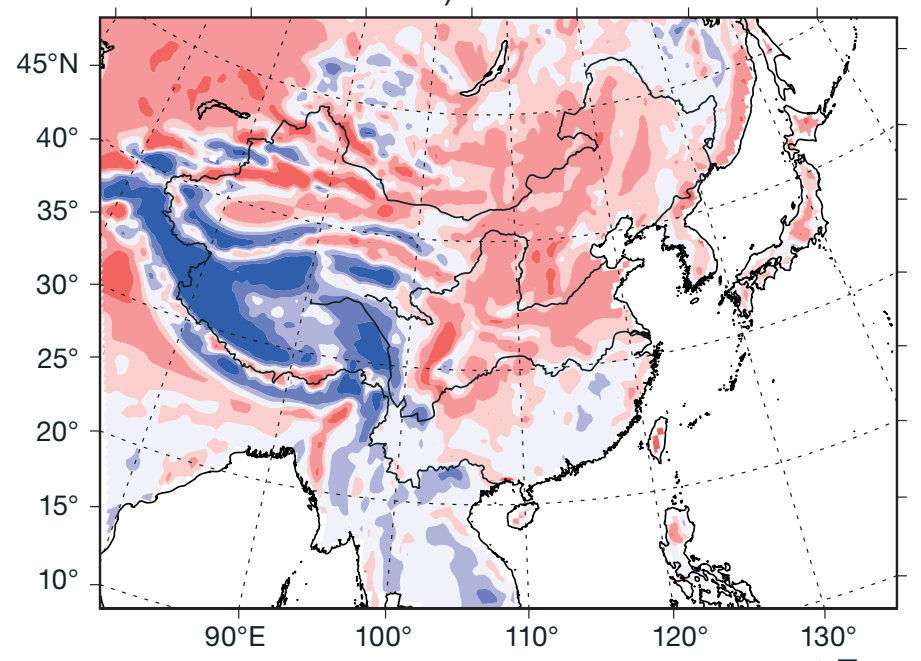

Fig. 2. Mean temperature in MJJAS for 1961-1990 over the RegCM3 domain (land only, ${ }^{\circ} \mathrm{C}$ ). (a) Observations; and differences between observations and simulations by (b) FvGCM, (c) FdR, (d) MIROC and (e) MdR

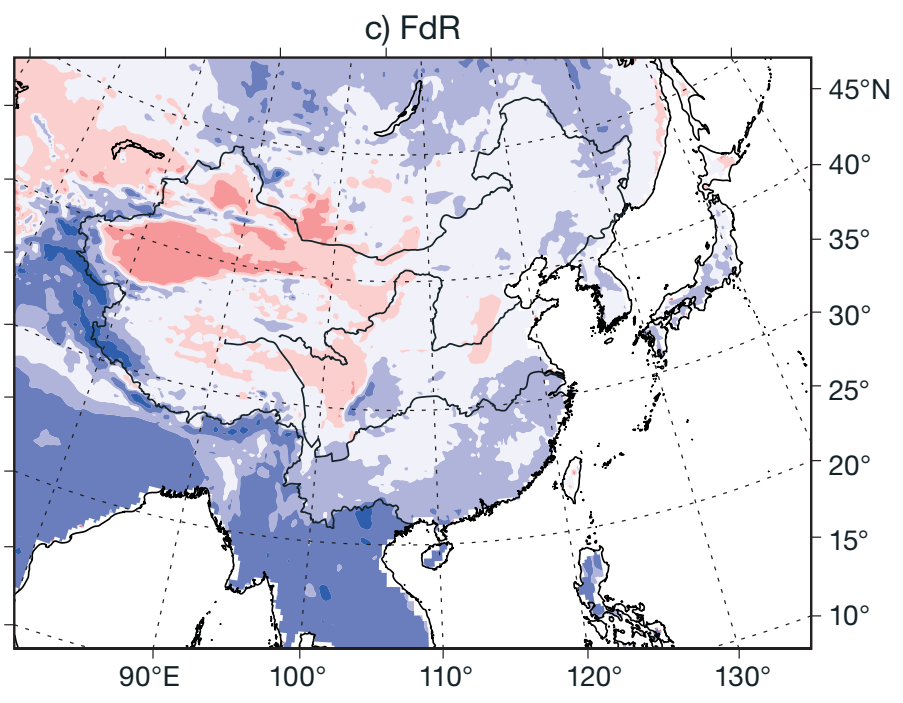

e) $\mathrm{MdR}$

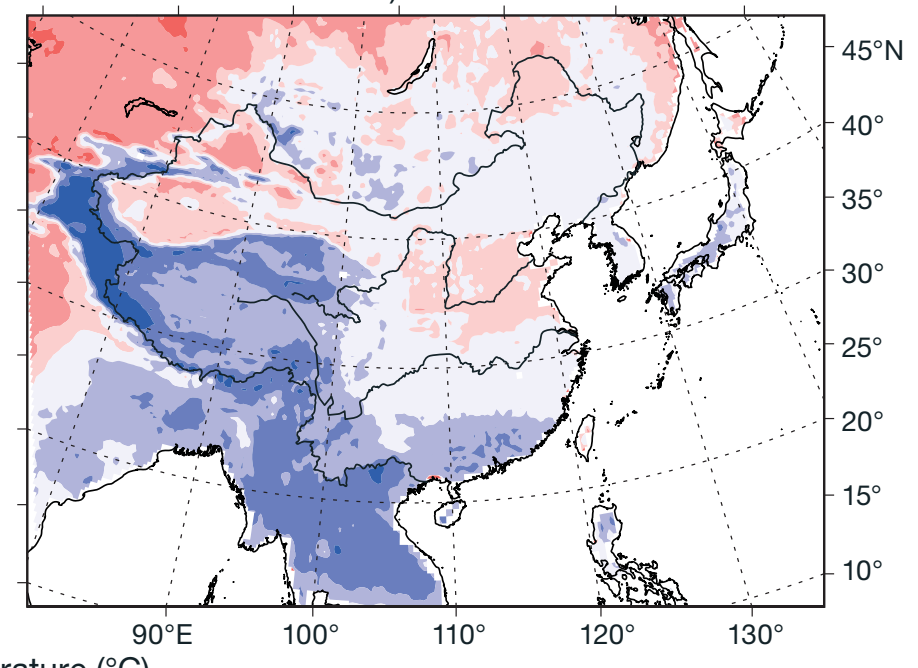


a) Xie

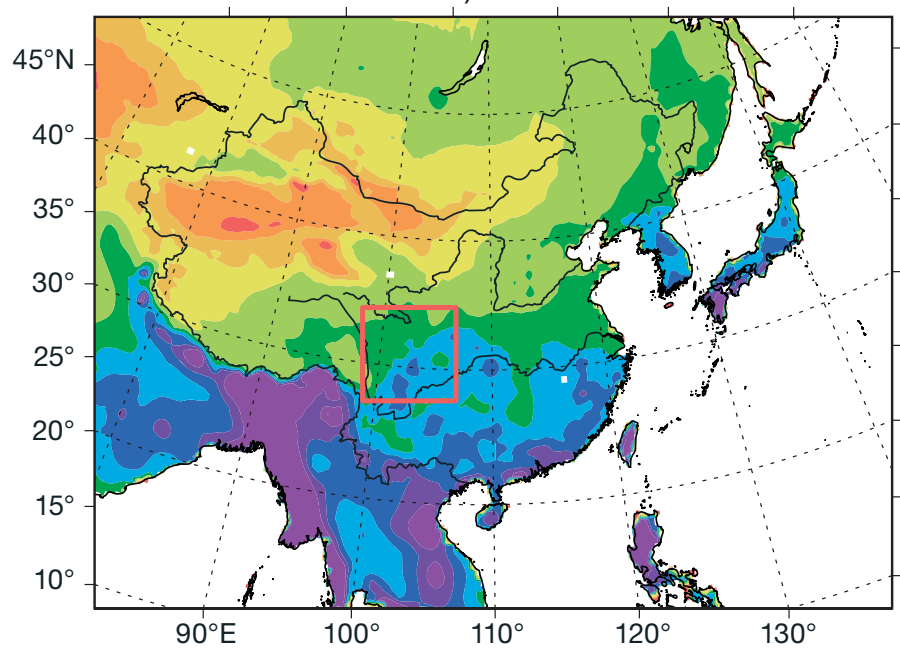

b) FvGCM

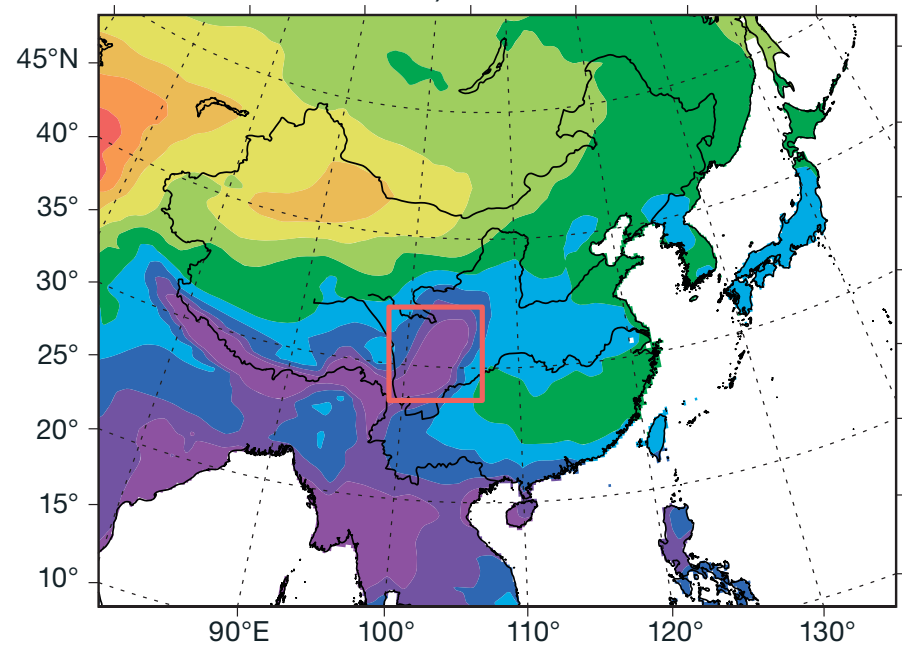

d) MIROC

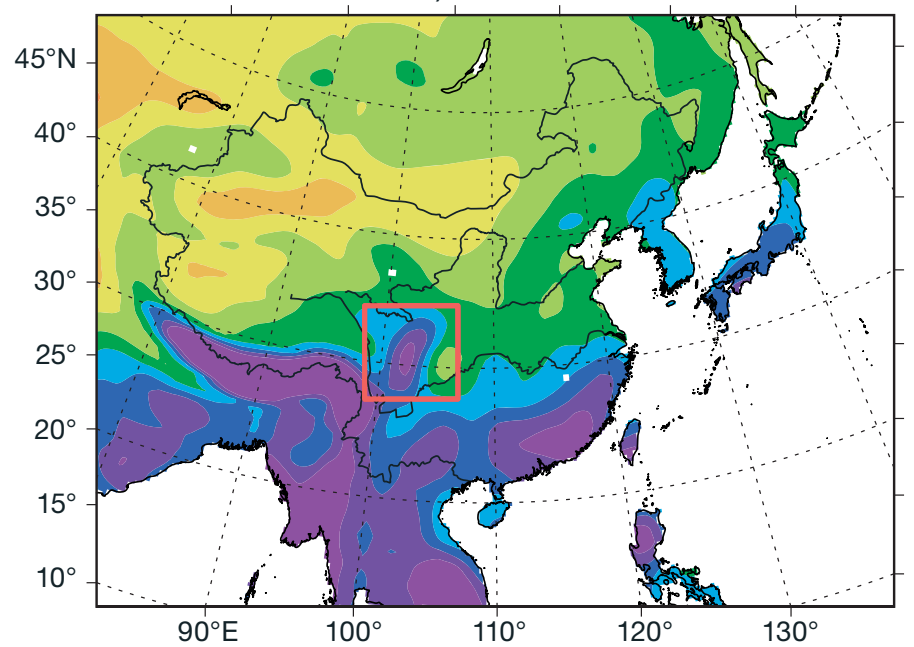

Fig. 3. Mean precipitation in MJJAS for 1961-1990 over the RegCM3 domain (land only, mm). (a) Observations; and simulations by (b) FvGCM, (c) FdR, (d) MIROC and (e) MdR. Red box: area where general circulation models tend to simulate excessive precipitation c) FdR

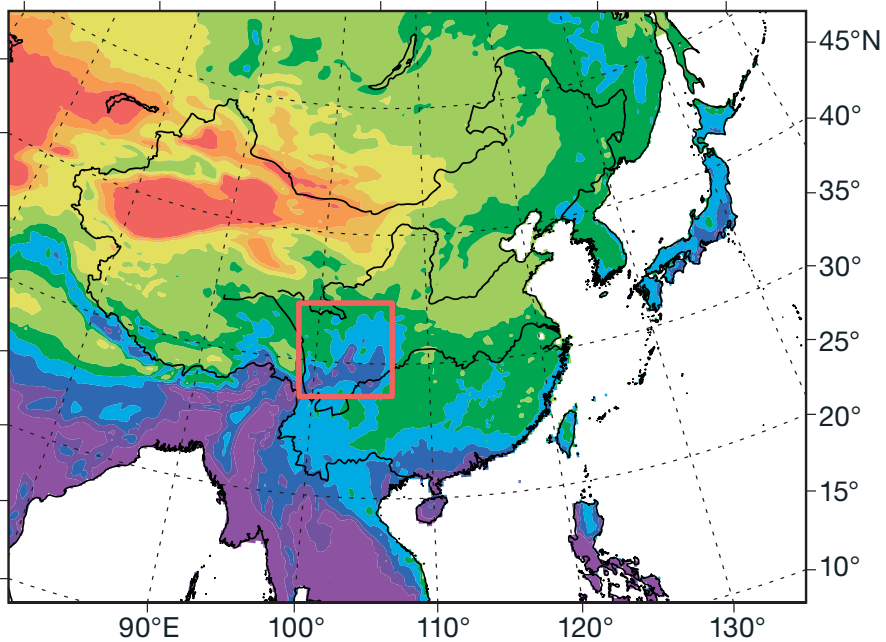

d) $\mathrm{MdR}$

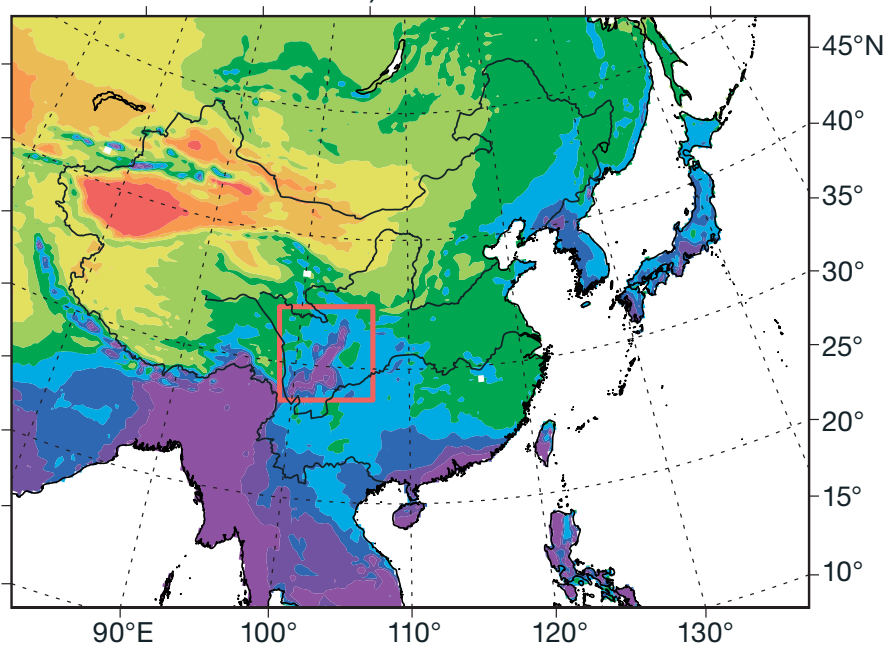

Precipitation $(\mathrm{mm})$ 
a) FvGCM

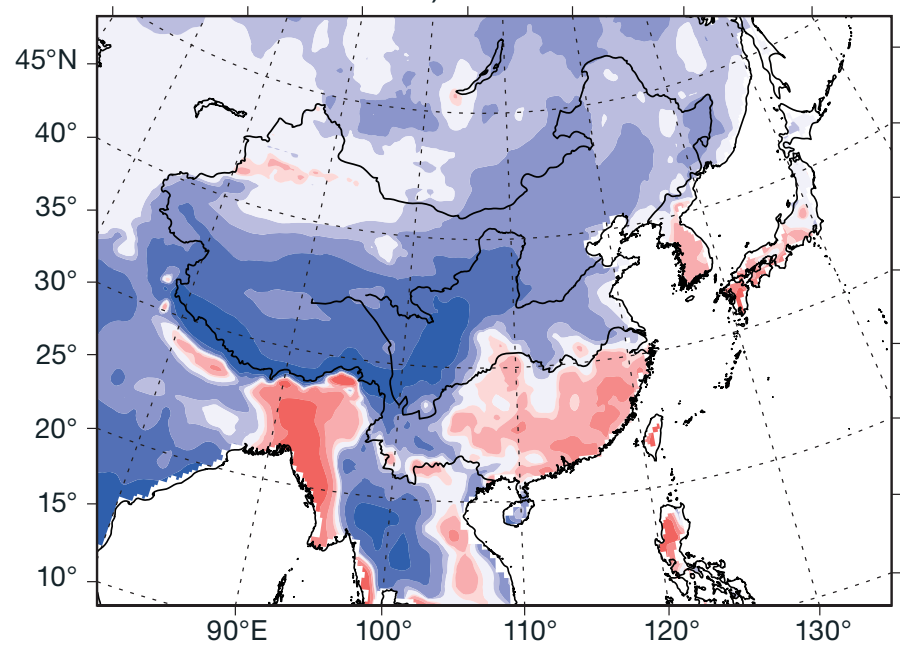

c) MIROC

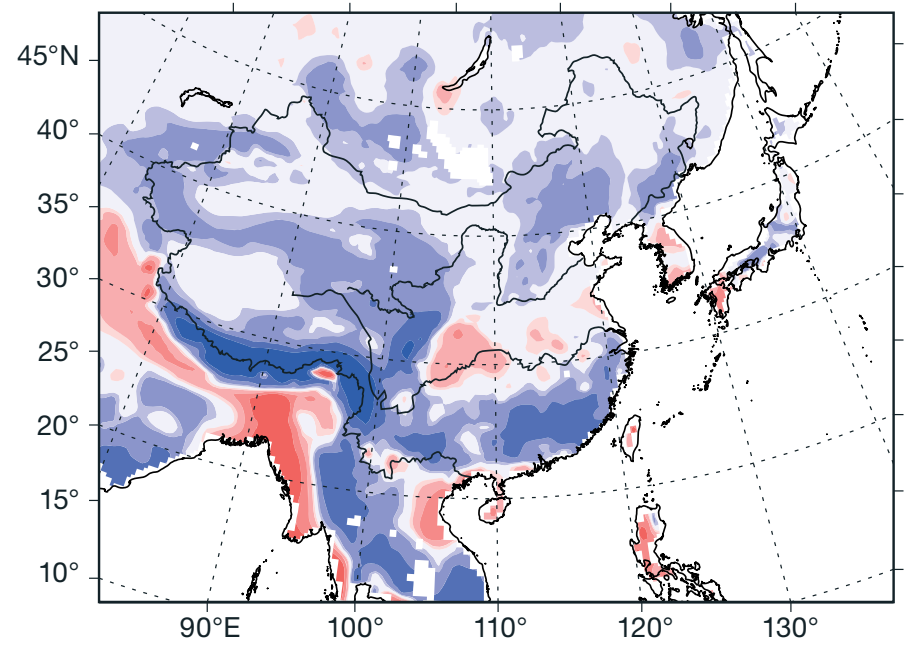

b) FdR

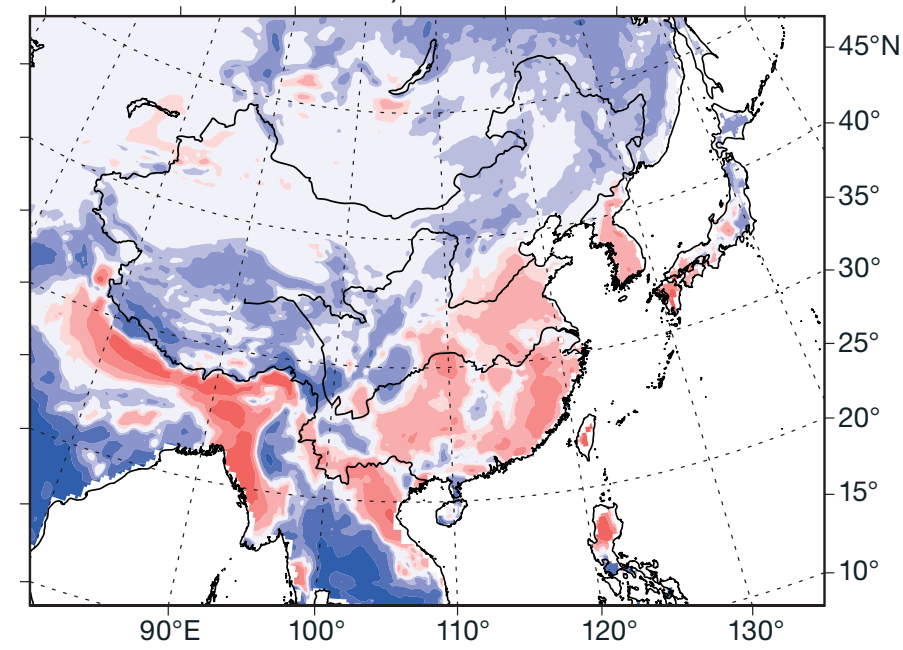

d) $M d R$

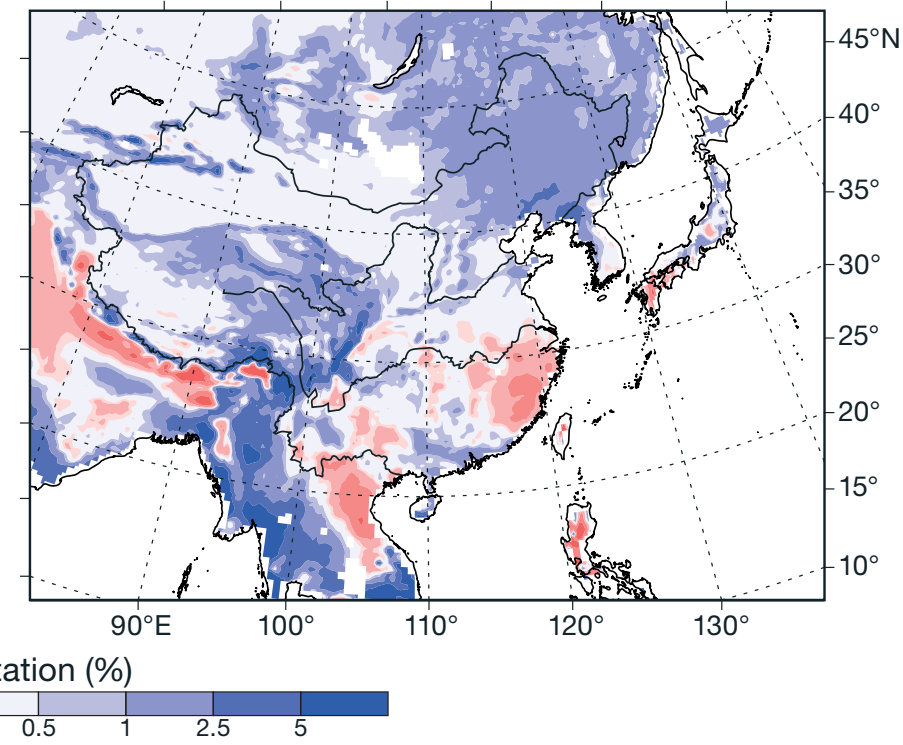

Fig. 4. Differences of precipitation (bias) in MJJAS for 1961-1990 over the RegCM3 domain (land only, \%) between observations and simulations for (a) FvGCM, (b) FdR, (c) MIROC (d) MdR

timation of precipitation along the Himalayas and over Northeast China (Figs. 3b,d \& 4a,c). In addition, both GCMs underestimate precipitation over Bangladesh and Myanmar, but overestimate it in the eastern part of the Indochina Peninsula. The 2 GCMs differ from each other over Southeast China; while the FvGCM underestimates precipitation there, the MIROC overestimates it.

Similar to the case of temperature, the precipitation simulation and bias in the regional model runs exhibit similar and discordant features compared to the driving GCMs. First, the extent and amount of the artificial precipitation center around the eastern edge of the Tibetan Plateau is reduced, particularly in FdR, thus increasing the agreement with observations there. Similarly to the GCMs, the RegCM3 runs show a positive bias over Northeast China and portions of the Tibetan Plateau. Over Southeast China land areas the FdR shows a prevailing negative precipitation bias, in agreement with the FvGCM, but less with the MdR.

It is also interesting to note that, although relatively large differences can be found between the FvGCM and MIROC simulations (Fig. 3b,d), the results from the nested RegCM3 runs show a greater level of consistency, both in the spatial details and magnitude of the precipitation patterns (Fig. 3c,e). This indicates that for relatively large domains and for variables 
such as summer precipitation, which are most affected by local processes and how these are described in the models, the internal model processes play an important role in the simulation. This is confirmed by the similarity of the model errors in the present simulations to those found when the model was driven by reanalysis data using the same model physical configuration, a similar domain, but a coarser resolution of $50 \mathrm{~km}$ (Zhang et al. 2008). A similar large effect of internal model physics in simulating summer precipitation was found, for example, for RCM experiments over Europe (Déqué et al. 2005) and Africa (Mariotti et al. 2011).

As in Table 1, Table 2 shows the CORs and STDs for precipitation. Based on these metrics, both FdR and MdR improve the simulation of precipitation compared to the driving GCMs, again indicating an added value by the RCMs. The largest value of COR (0.858) and smallest value of STD (51.1) are found between FdR and MdR, which shows the importance of the internal model processes and configuration. We note that the COR between MIROC and the observations (0.812) is greater than that of FvGCM $(0.710)$ and that a larger COR value is found for MdR (0.864) compared to FdR (0.783). This would indicate some effects of the quality of the lateral boundary forcing, although relatively minor. Finally, we also note that, in general, the values of CORs are relatively high in all cases of Table 2, indicating a generally good performance in simulating summer monsoon precipitation patterns by all models.

\section{COMPARISON OF CLIMATE CHANGE SIGNALS}

\subsection{Mean surface air temperature}

Firstly, changes (2071-2100 minus 1961-1990) in mean MJJAS temperatures as simulated by the driving GCMs and nested RegCM3 are presented in Fig. 5. Substantial warming is found in all model sim-

Table 2. Spatial correlation coefficients (CORs) / standard depatures (STD) (mm) between observed and simulated precipitation, and across the model simulations over the model domain

\begin{tabular}{|lccccc|}
\hline & Observation & FvGCM & MIROC & FdR & MdR \\
\hline Observation & - & $0.710 / 71.0$ & $0.812 / 94.7$ & $0.783 / 60.8$ & $0.864 / 50.7$ \\
FvGCM & $0.710 / 71.0$ & - & $0.812 / 91.6$ & $0.811 / 55.7$ & $0.742 / 68.9$ \\
MIROC & $0.812 / 94.7$ & $0.812 / 91.6$ & - & $0.730 / 89.2$ & $0.761 / 99.2$ \\
FdR & $0.783 / 60.8$ & $0.811 / 55.7$ & $0.730 / 89.2$ & - & $0.858 / 51.1$ \\
MdR & $0.864 / 50.7$ & $0.742 / 68.9$ & $0.761 / 99.2$ & $0.858 / 51.1$ & - \\
\hline
\end{tabular}

ulations. The simulated patterns of warming show some consistency among the models, with generally greater values at high latitudes and over the land compared to the oceans. The warming in MIROC and MdR is greater than in FvGCM and FdR, although the former pair has a lower emission scenario. As already mentioned, this is due to the larger climate sensitivity of MIROC (Randall et al. 2007) and might be expected to lead to stronger precipitation responses. Mean temperature increases for FvGCM, FdR, MIROC and MdR averaged over China are 3.3, $3.3,4.6$ and $4.8^{\circ} \mathrm{C}$, respectively.

Differences in the spatial distribution between RegCM and the driving GCMs are not large, except over the Tibetan Plateau and Northeast China between the MIROC and MdR simulations, suggesting a dominant forcing by the GCMs in terms of temperature change for most of the domain. Also, we do not find a consistent relationship between the temperature change signals and the present-day biases (comparison of Figs. $2 \& 5$ ). This lack of relationship between temperature bias and change signal in climate model projections has also been noted by Giorgi \& Coppola (2010) and indicates that the change signal is determined more by the model response to the greenhouse gas forcing than by artificial effects associated with the model biases.

The differences between MIROC and MdR are large over the Tibetan Plateau. This may be related to the different feedback effects between the warming and melting of snow cover due to the associated reduction in surface albedo (Giorgi et al. 1997). However, clear identification of the reasons for these different model responses is difficult and may require an analysis of the surface energy budgets in the model, which is outside the purpose of the present paper.

Table 3 shows the correlations of warming patterns across models for the whole domain and continental China. The CORs between the pair FvGCMFdR and the pair MIROC-MdR are 0.902 and 0.719 over the model domain, respectively, illustrating the strong forcing by the global models. The smaller correlation in the latter pair is due mostly to the contribution of the Tibetan Plateau (see Fig. 5), where effects related to snow melt feedbacks simulated by the models might influence the change signals. Smaller correlations of 0.576 are found across the 
a) FvGCM

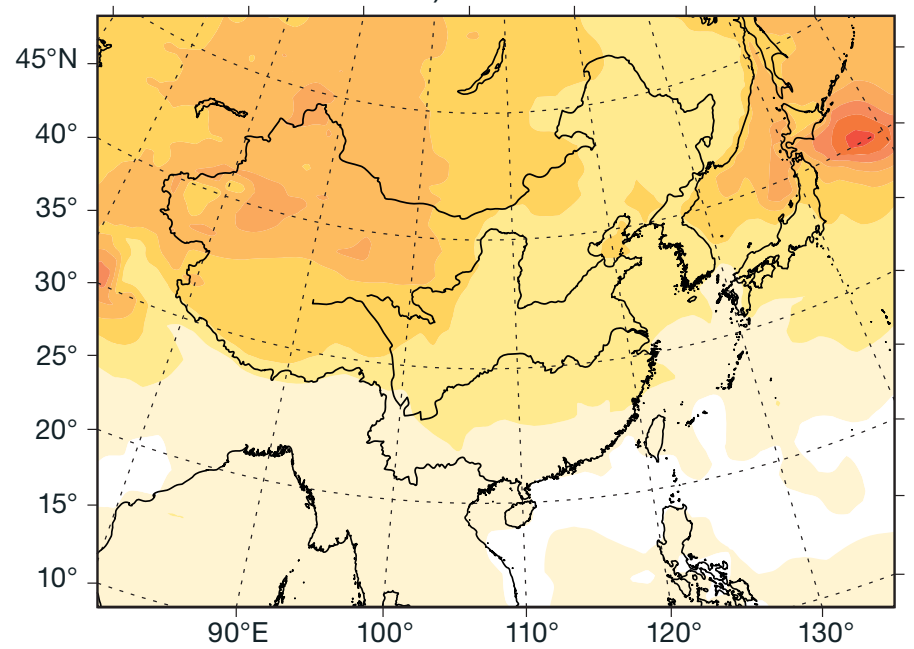

c) MIROC

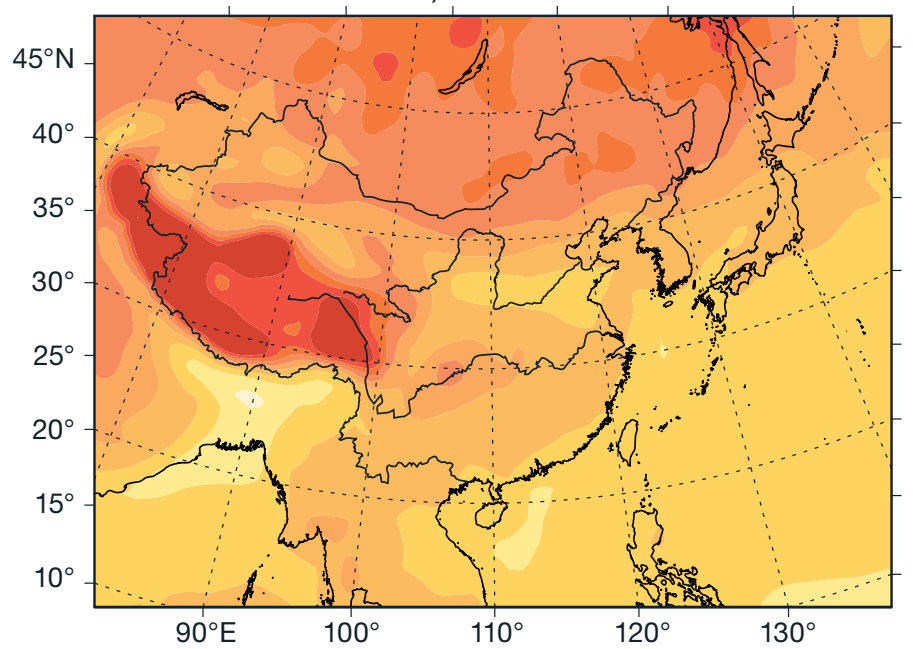

a) FdR

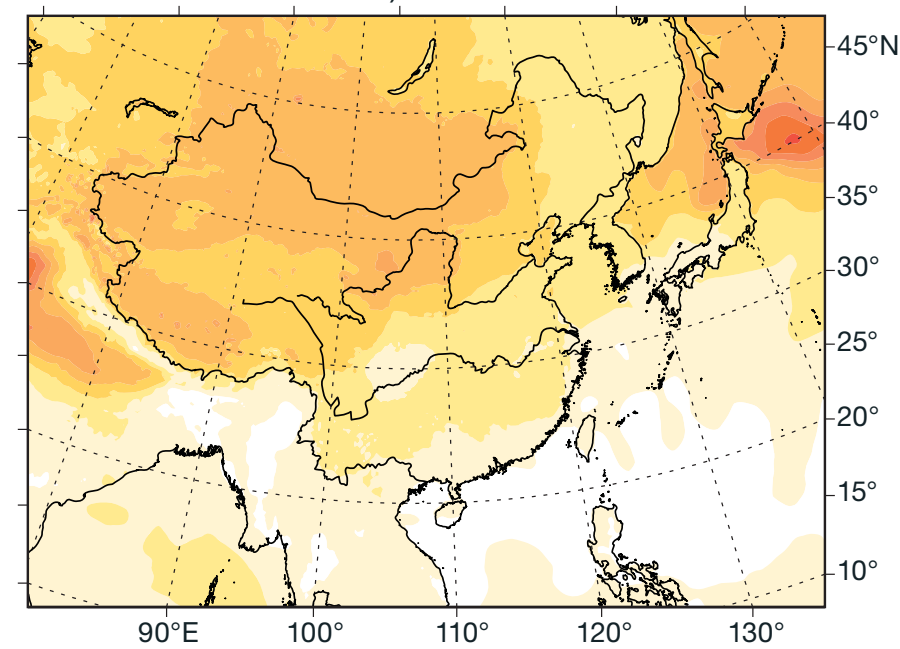

c) MdR

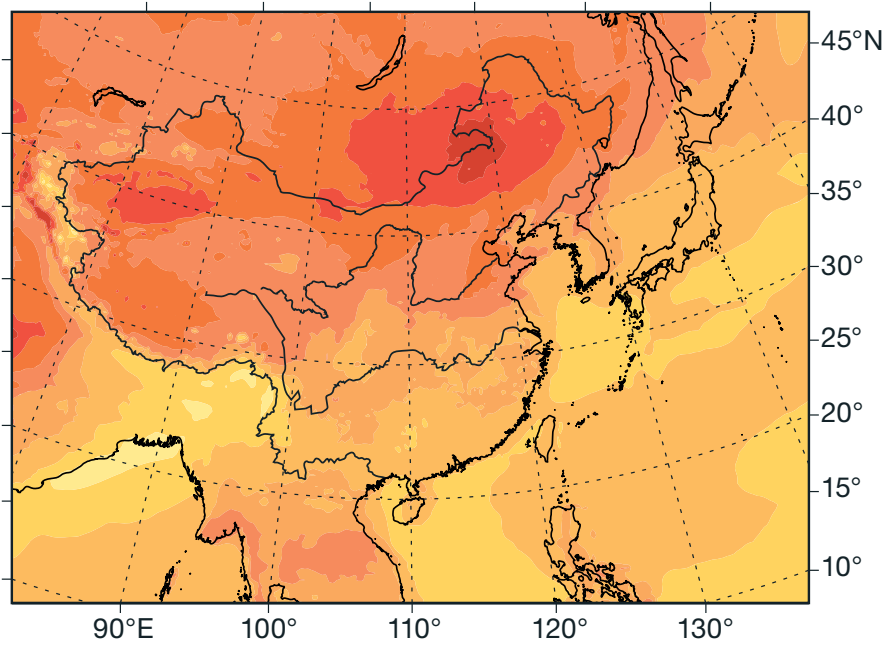

$\Delta$ Temperature $\left({ }^{\circ} \mathrm{C}\right)$

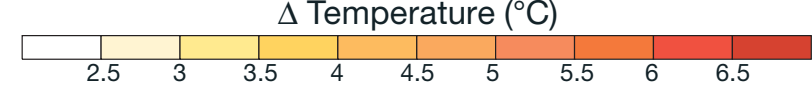

Fig. 5. Simulated changes (2071-2100 relative to 1961-1990) in mean temperature ( $\left.{ }^{\circ} \mathrm{C}\right)$ for MJJAS by (a) FvGCM, (b) FdR, (c) MIROC and (d) MdR

Table 3. Spatial correlation coefficients (CORs) of temperature change between model simulations (over the model domain/over continental China)

\begin{tabular}{|lcccc|}
\hline & FvGCM & MIROC & FdR & MdR \\
\hline FvGCM & - & $0.576 / 0.589$ & $0.902 / 0.895$ & $0.587 / 0.592$ \\
MIROC & $0.576 / 0.589$ & - & $0.579 / 0.620$ & $0.719 / 0.754$ \\
FdR & $0.902 / 0.895$ & $0.579 / 0.620$ & - & $0.634 / 0.678$ \\
MdR & $0.587 / 0.592$ & $0.719 / 0.754$ & $0.634 / 0.678$ & - \\
\hline
\end{tabular}

2 global models and of 0.634 between the 2 regional simulations. Overall, the COR values in the full domain case are consistent with those limited to the territory of China.

\subsection{Mean precipitation}

Changes in mean precipitation and $700 \mathrm{hPa}$ wind fields in MJJAS are shown in Fig. 6. A predominant increase of summer monsoon precipitation is observed in both FvGCM and MIROC simulations over China, consistent with most other CMIP3 models (e.g. Christensen et al. 2007, Xu et al. 2010). In eastern China, the increase is more pronounced ( $>25 \%$ ) over the Huanghuai and Shandong Peninsula (Fig. 6a,c). As can be observed in the figures, a greater increase of precipitation is projected 
by both models in North China compared to South China, indicating that the present pattern of 'southern flood and northern drought' is not found in the GCM climate projections.

Over western China, a larger increase of precipitation is simulated by MIROC, in excess of $50 \%$ along the edges of the western part of the Tibetan Plateau. A slight decrease of precipitation can be found over the central plateau in the MIROC simulation and over the southeastern China coasts in both models. Note that in both GCMs an increase in south-westerly flow occurs over eastern China, especially in MIROC.

As discussed by Gao et al. (2008), in FvGCM the general increase of precipitation over China, except south of the Yangtze River, can be largely attributed to the westward wind change which brings extra moisture from the sea in the east (Japan Sea and Northwest Pacific). This partly applies also over Northeast and Northwest China in the MIROC simulation. However, as shown in Fig. 6c, the precipitation increase over the Huanghuai and Shandong Peninsula is mostly caused by the convergence of moisture brought by southwesterly flow (increased monsoon flow; Kimoto 2005). While the increased westerly wind also contributes to the increase of precipitation over Northwest China, it leads to the larger increase of precipitation over the edges of the western Tibetan Plateau.

A region where the 2 GCM simulations show a substantial difference is the Bay of Bengal, where FvGCM projects increased westerly flow, while MIROC simulates increased anti-cyclonic circulation. This anti-cyclonic circulation causes a decrease of precipitation over the western Indochina Peninsula and an increase over the eastern coastal regions of India. It also contributes to the large precipitation increase belt along the southern edge of the Tibetan Plateau. Conversely, FvGCM simulates an increase in precipitation over the Indochina Peninsula and a smaller response around the Tibetan Plateau.

Moving to the RegCM simulations, both similarities and substantial differences can be found between FdR and the driving FvGCM (Fig. 6a,b). As discussed by Gao et al. (2008), the differences can be primarily explained by the stronger topographic forcing and the resulting circulation changes in RegCM3. For example, the east-northeast wind change, which brings extra moisture from the sea in FvGCM over Northeast China, is located further south and forms a stronger cyclonic circulation over the Huanghuai and Shandong Peninsula in FdR. It results in a much narrower band of precipitation increase there, finally forming a see-saw pattern of precipitation change over eastern China, ranging from the northeast down to the southern coasts. On the other hand, the precipitation changes over the Indo-China Peninsula and the northern regions of the domain are similar in the driving and nested models, likely because of their proximity to the lateral boundaries.

Comparison between the MIROC and MdR simulations also shows similarities as well as noticeable differences (Fig. 6c,d). Both models show the increased anti-cyclonic circulation over the Bay of Bengal, leading to increased precipitation over the eastern India coastal regions. Similarly, the band of increasing precipitation around the Tibetan Plateau occurs in both the nested and driving models, but it is more sharply defined in the RegCM due to its higher resolution. In Northeast China, both models show an increasing anti-cyclonic circulation cell, which is, however, much more pronounced in the regional model, causing a more extended area of decreasing precipitation change than in MIROC.

This large anti-cyclonic circulation change system in MdR affects regions all the way to the Yangtze River basin, where the change in low-level wind is in the opposite direction compared to MIROC. Consequently, little precipitation change is observed over the Huanghuai and Shandong Peninsula in the MdR compared to the MIROC simulation. Over South China, the southwest flow originating from the Bay of Bengal (increased southwest monsoon) is much weaker in MdR compared to MIROC due to the stronger topographic barriers of the east-west oriented Himalayas aligning the flow in a more northwesterly direction, and, on the other hand, to the north-south oriented mountains over Southwest China. In the MdR, strengthened by the anti-cyclonic system to the north, the moisture convergence center moves to the south and leads to an increase of precipitation south of the Yangtze River. The patterns of precipitation change appear thus spatially shifted in the 2 models.

A comparison between the FdR and MdR precipitation change patterns (Fig. 6b,d) shows a small level of agreement over eastern China, even though the present-day precipitation patterns in the 2 models are similar (see Fig. 3c,e). Concerning the issue of future changes following a 'southern flood and northern drought' pattern, in North China minor changes or a slight decrease of precipitation is simulated in the FdR, while an increase of $\sim 10 \%$ is simulated in the MdR. The precipitation change over South China shows opposite signs in the 2 simulations, with decreasing precipitation in the FdR and increasing in 
a) FvGCM

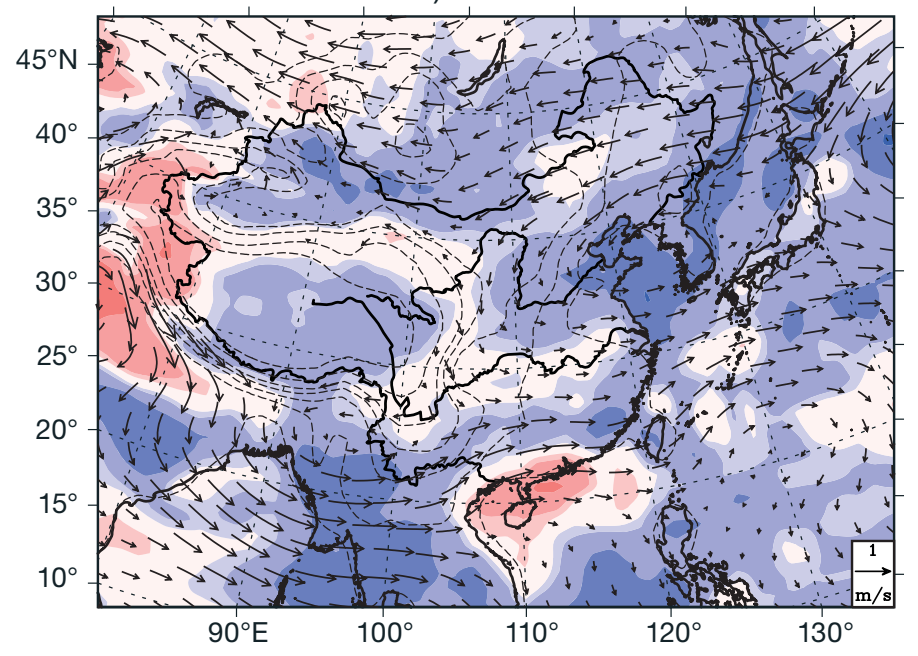

c) MIROC

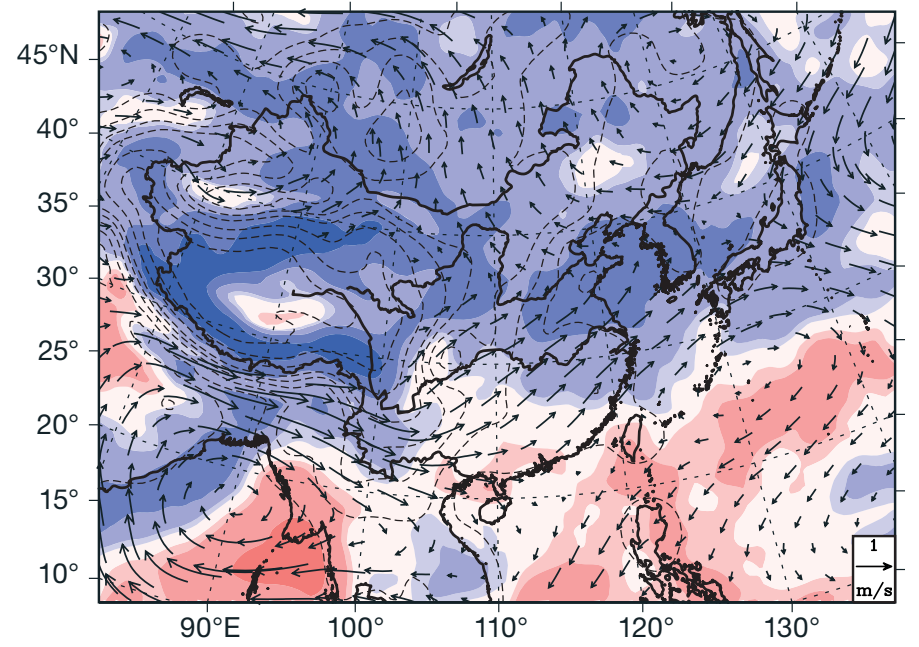

b) FdR

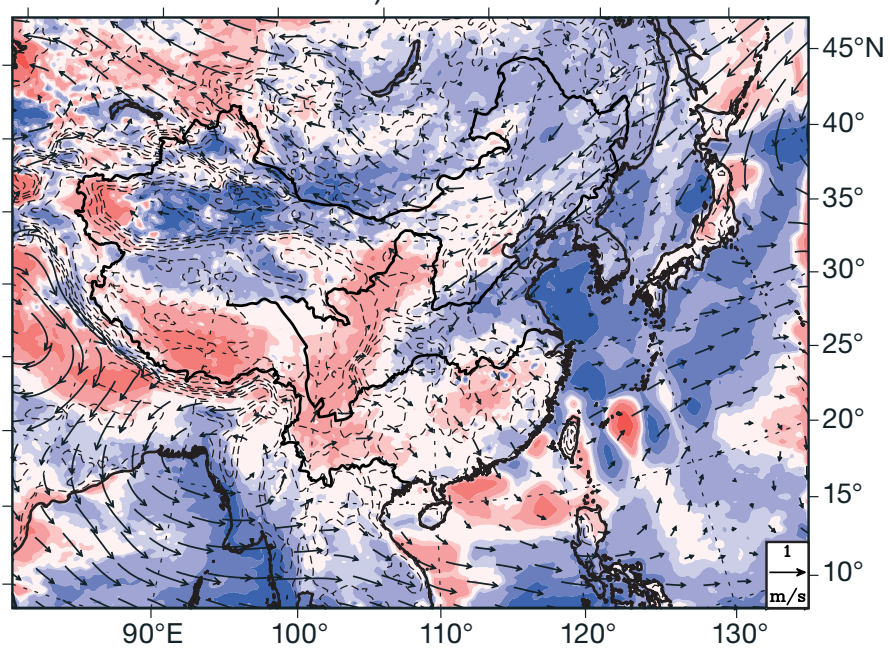

d) $\mathrm{MdR}$

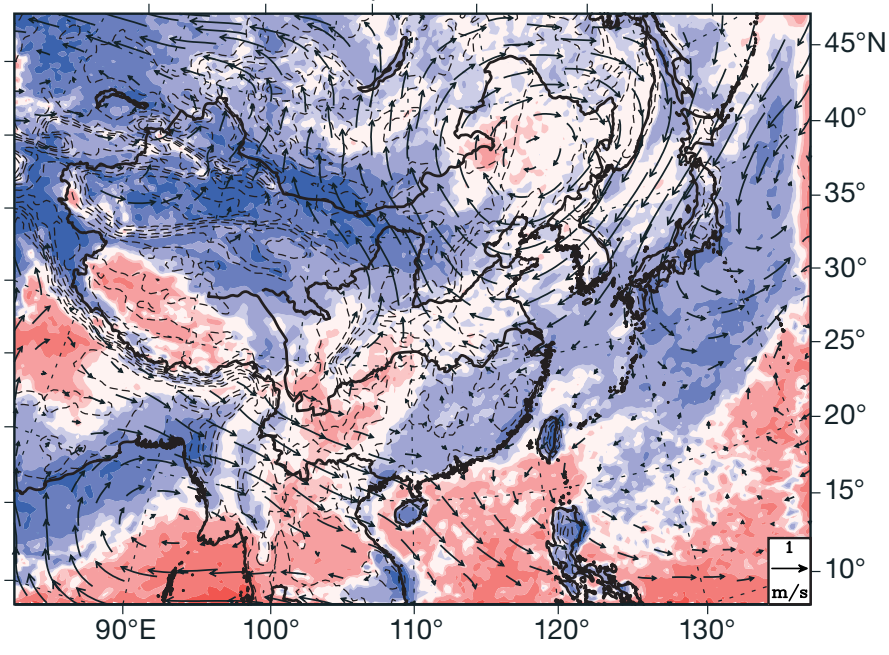

$\Delta$ Precipitation (\%)

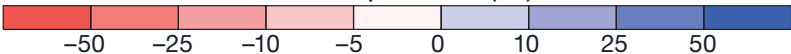

Fig. 6. Simulated changes (2071-2100 relative to 1961-1990) in mean precipitation (shading, \%) and 700 hPa wind (arrows, $\mathrm{m} \mathrm{s}^{-1}$ ) for MJJAS by (a) FvGCM, (b) FdR, (c) MIROC and (d) MdR. The dashed contour lines indicate model topography at the intervals $100,500,1000,1500,2000,3000,4000$ and $5000 \mathrm{~m}$

the MdR. Thus, the RegCM3 simulations suggest great uncertainty in the evolution of the 'southern flood and northern drought' pattern under global warming.

Similar to the case of precipitation, as a quantitative measure of consistency we calculate the correlation coefficients between the precipitation change patterns in different pairs of models over the model domain and over continental China (Table 4).

When considering the whole domain, the COR of FvGCM-FdR (0.480) and MIROC-MdR (0.340) are largest, as a result of the dominant boundary forcing. Conversely, when limiting the correlation to conti- nental China, which is located in the innermost regions of the domain, the largest correlations are found between FdR and MdR. As shown in Fig. 6, this is mostly due to the similar change patterns over western China, where local topographic effects are maximum. In other words, while the boundary forcing dominates the overall precipitation patterns, especially in the outermost regions of the domain, internal processes dominate in the interior regions.

Fig. $7 \mathrm{a}$, $\mathrm{b}$ show the intermodel agreement in simulated precipitation change of magnitudes greater than $\pm 5 \%$ between FvGCM and MIROC and between FdR and MdR, respectively. The 2 GCMs 
Table 4. Spatial correlation coefficients (CORs) of precipitation change between model simulations over the model domain and continental China

\begin{tabular}{|lcccc|}
\hline & FvGCM & MIROC & FdR & MdR \\
\hline FvGCM & - & $0.041 /-0.051$ & $0.480 / 0.254$ & $-0.090 / 0.123$ \\
MIROC & $0.041 /-0.051$ & - & $-0.014 / 0.056$ & $0.340 / 0.122$ \\
FdR & $0.480 / 0.254$ & $-0.014 / 0.056$ & - & $0.097 / 0.483$ \\
MdR & $-0.090 / 0.123$ & $0.340 / 0.122$ & $0.097 / 0.483$ & - \\
\hline
\end{tabular}

grid spacing (20 vs. $25 \mathrm{~km}$ ). The focus of our analysis is on summer monsoon precipitation.

As a first broad conclusion, our study supports previous findings that model resolution is very important in the simulation of present-day climatology and in the projection of future change patterns. For present-day conditions (1961-1990), the nested

agree in simulating a positive increase over most of the domain, with the noticeable exception of Southeast China where a small area of decrease is found. This area of decrease is moved to the south over the ocean in the regional model runs (Fig. 7b), which also show a consistent precipitation decrease signal over western and southwestern China around the Tibetan Plateau. Therefore, confirming the results of Table 4, over these areas the greater topographic forcing in the regional models dominates compared to the large-scale forcing from the lateral boundaries.

\section{DISCUSSION AND CONCLUSIONS}

In the present paper, we compare results from 2 high-resolution RCM climate change simulations over East Asia in which RegCM3 is driven by 2 different GCMs (FvGCM under the A2 scenario and MIROC under the A1B scenario) and uses the same configuration, although slightly different horizontal

a) FvGCM-MIROC

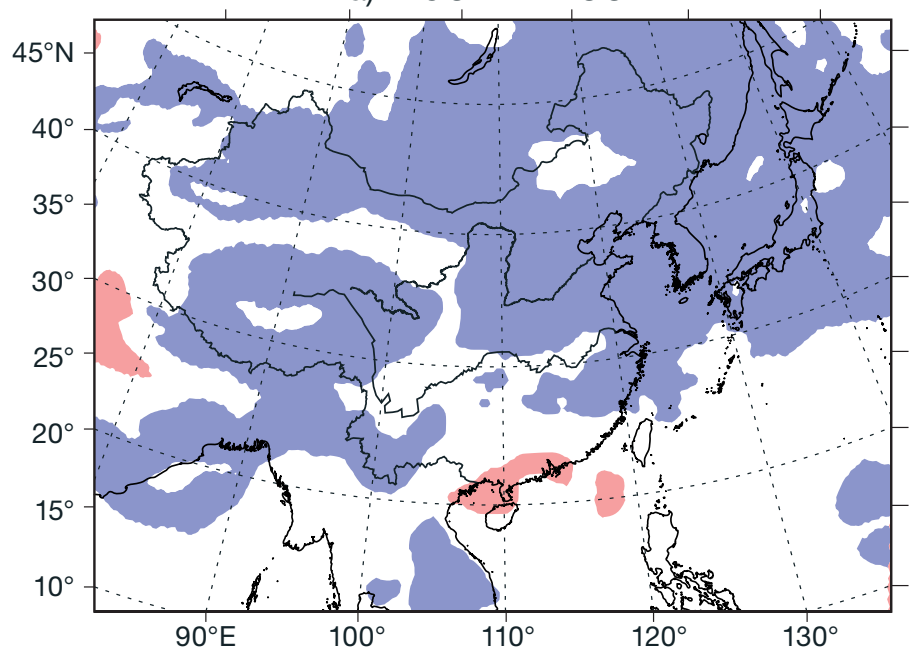

model provides finer scale detail of surface air temperature and precipitation than the driving models, often improving agreement with observations, as for example measured by the correlation coefficients and STDs between simulated and observed precipitation patterns. Interestingly, for present-day precipitation we found a greater agreement between the 2 RCM simulations than between each RCM run and the corresponding GCM driving model. This implies that for summer monsoon precipitation the internal model processes play an important role in determining the RCM behavior compared to the large-scale forcing from the lateral boundaries, at least in terms of present-day climatology.

For future climate conditions (2071-2100 vs. 19611990) both global models produce substantial warming of comparative magnitude, although based on different scenarios. In fact MIROC shows a $\sim 1^{\circ} \mathrm{C}$ greater warming that FvGCM over our region of interest. The warming patterns simulated by the regional models essentially follow those of the driving models

\section{b) RegCM}

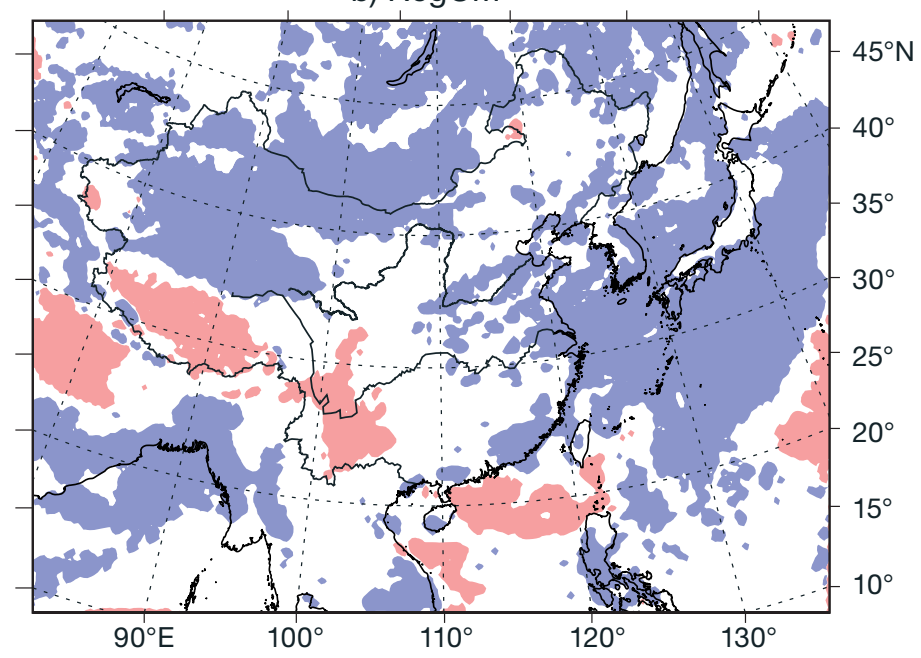

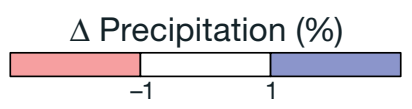

Fig. 7. Agreement in the sign of projected precipitation change across model simulations (a) between FvGCM and MIROC and (b) between FdR and MdR (RegCM). Blue (red) indicates that both models simulate a > $\%$ increase (decrease) 
as a result of the lateral boundary forcing. More relevant for the immediate focus of the present paper, both GCMs simulate a predominant (although not ubiquitous) increase of monsoon precipitation over East Asia, which is consistent with the dominant signal found in the CMIP3 ensemble (Giorgi \& Bi 2005, Christensen et al. 2007). On the other hand, the spatial structure of the projected precipitation change patterns differs across the $2 \mathrm{GCMs}$, with areas of maximum and minimum increase, or even decrease, occurring in different sub-regions of East Asia.

In our experiments, the use of the high-resolution regional model tends to amplify regional differences across the projections. In general, the regional model tends to produce a less ubiquitous increase of precipitation across East Asia and a more balanced distribution of regions with precipitation increases and decreases. A projected increase of precipitation over Northwest China and decrease over the western Tibetan Plateau and Southwest China is found in both RegCM3 simulations, even though the global models show different change patterns there, and this result would be in agreement with observed trends in the past few decades (Shi et al. 2002, Gao et al. 2008). It should be noted that this pattern of change was also simulated by Feng et al. (2011) using a high-resolution atmospheric GCM (T319 version of ECHAM5).

Greater uncertainty is found over eastern China, where monsoon climate dominates. The 2 GCMs employed in the study project a weakening or reversal of the so-called 'southern flood and northern drought' pattern, and the RegCM3 simulations show even more contrasting results. Therefore, the suggestion of this 'southern flood and northern drought' pattern being associated with global warming remains to be further investigated in future studies.

An important aspect of our results is that the precipitation changes projected by RegCM3 and the driving GCM show similarities (e.g. over the Bay of Bengal and the Indochina Peninsula), but also substantial differences, particularly on the Tibetan Plateau and in eastern China. This occurs in both simulations and can be mostly attributed to the different topographies in the models. More generally, differences of change patterns between the nested and driving models can be of the same order of magnitude as the differences between the 2 GCM runs, implying that for summer precipitation the internal model processes play an important role (e.g. Déqué et al. 2005).

Our results thus support the conclusion that regional climate change projections based on current ensembles of global models should be considered very cautiously. While the use of high-resolution nested models adds physically consistent spatial detail to the projection, it also adds an important element of uncertainty which needs to be properly characterized (Giorgi et al. 2008). This will require the completion of large multi-GCM/RCM ensembles, calling for the implementation of large internationally coordinated projects such as the recently devised coordinated regional climate downscaling experiment (CORDEX; Giorgi et al. 2008, 2009).

Acknowledgements. This research was jointly supported by the Special Research Program for Public-Welfare Forestry (Grant No. 200804001), the National Basic Research Program of China (Grant No. 2010CB950903), the National Natural Science Foundation of China (Grant No. 40975041), and China-UK-SWISS Adapting to Climate Change in China Project (ACCC). The authors acknowledge the modeling group of MIROC3.2_hires for preparing and providing the initial and boundary data to drive RegCM3 (Dr. Seita Emori, Dr. Manabu Abe, and others).

\section{LITERATURE CITED}

Christensen JH, Hewitson B, Busuioc A, Chen A and others (2007) Regional climate projections. In: Solomon S, Qin D, Manning M, Chen Z and others (eds) Climate change 2007: the physical science basis. Contribution of Working Group I to the 4th assessment report of the Intergovernmental Panel on Climate Change. Cambridge University Press, Cambridge, p 847-940

Coppola E, Kucharski F, Giorgi F, Molteni F (2005) Bimodality of the North Atlantic Oscillation in simulations with greenhouse gas forcing. Geophys Res Lett 32:L23709. doi:10.1029/2005GL024080

> Déqué M, Jones RG, Wold M, Giorgi F and others (2005) Global high resolution versus limited area model climate change projections over Europe: quantifying confidence level from PRUDENCE results. Clim Dyn 25:653-670

Dickinson RE, Henderson-Sellers A, Kennedy PJ (1993) Biosphere-atmosphere transfer scheme (BATS) Version 1 as coupled to the NCAR community climate model. Technical Note NCAR/TN-387 + STR, NCAR, Boulder, CO

Feng L, Zhou TJ, Wu B, Li T, Luo JJ (2011) Projection of future precipitation change over China with a high-resolution global atmospheric model. Adv Atmos Sci 28: $464-476$

Gao XJ, Zhao ZC, Ding YH, Huang RH, Giorgi F (2001) Climate change due to greenhouse effects in China as simulated by a regional climate model. Adv Atmos Sci 18: 1224-1230

Gao XJ, Xu Y, Zhao ZC, Pal JS, Giorgi F (2006) On the role of resolution and topography in the simulation of East Asia precipitation. Theor Appl Climatol 86:173-185

Gao XJ, Shi Y, Song RY, Giorgi F and others (2008) Reduction of future monsoon precipitation over China: comparison between a high resolution RCM simulation and the driving GCM. Meteorol Atmos Phys 100:73-86

> Giorgi F, Bi XQ (2005) Updated regional precipitation and temperature changes for the 21st century from ensembles of recent AOGCM simulations. Geophys Res Lett 32: 


\section{L21715. doi:10.1029/2001GL013150}

Giorgi F, Coppola E (2010) Does the model regional bias affect the projected regional climate change? An analysis of global model projections. Clim Change 100:787-795

> Giorgi F, Marinucci MR, Bates GT (1993a) Development of a second-generation regional climate model (RegCM2). Part I: boundary layer and radiative transfer processes. Mon Weather Rev 121:2794-2813

- Giorgi F, Marinucci MR, Bates GT, DeCanio G (1993b) Development of a second-generation regional climate model (RegCM2). II. Convective processes and assimilation of lateral boundary conditions. Mon Weather Rev 121:2814-2832

Giorgi F, Hurrell JW, Marinucci MR, Beniston M (1997) Elevation dependency of the surface climate change signal: a model study. J Clim 10:288-296

Giorgi F, Whetton PH, Jones RG, Christensen JH and others (2001) Emerging patterns of simulated regional climatic changes for the 21st century due to anthropogenic forcings. Geophys Res Lett 28:3317-3320

Giorgi F, Diffenbaugh NS, Gao XJ, Coppola E and others (2008) The regional climate change hyper-matrix framework. EOS Trans Am Geophys Union 89:445-446

Giorgi F, Jones C, Asrar GR (2009) Addressing climate information needs at the regional level: the CORDEX framework. WMO Bull 58:175-183

> Grell GA (1993) Prognostic evaluation of assumptions used by cumulus parameterizations. Mon Weather Rev 121: 764-787

> Hirakuchi H, Giorgi F (1995) Multi-year present day and $2 \times$ $\mathrm{CO}_{2}$ simulations of monsoon-dominated climate over eastern Asia and Japan with a regional climate model nested in a general circulation model. J Geophys Res 100:21105-21126

Holtslag AAM, de Bruijin EIF, Pan HL (1990) A high resolution air mass transformation model for short-range weather forecasting. Mon Weather Rev 118:1561-1575

IPCC (Intergovernmental Panel on Climate Change) (2000) In: Nakicenovic N, Swart R (eds) Special report on emissions scenarios. Cambridge University Press, Cambridge

K-1 Model Developers (2004) K-1 coupled model (MIROC) description. In: Hasumi H, Emori S (eds) K-1 Technical Report 1. Center for Climate System Research, University of Tokyo, Tokyo, p 1-34

Kato H, Nishizawa K, Hirakuchi H, Kadokura S and others (2001) Performance of RegCM2.5/NCAR-CSM nested system for the simulation of climate change in East Asia caused by global warming. J Meteorol Soc Jpn 79:99-121

Kiehl JT, Hack JJ, Bonan GB, Boville BA and others (1996) Description of NCAR community climate model (CCM3). Technical Note NCAR/TN-420 + STR, NCAR, Boulder, CO

Kimoto M (2005) Simulated change of the East Asian circulation under global warming scenario. Geophys Res Lett 32:L16701. doi:10.1029/2005GL023383

> Lenderink G, van Meijgaard E (2010) Linking increases in hourly precipitation extremes to atmospheric temperature and moisture changes. Environ Res Lett 5:025208. doi:10.1088/1748-9326/5/2/025208

Mariotti L, Coppola E, Sylla MS, Giorgi F, Piani C (2011) Regional climate model simulation of projected 21st century climate over an all-Africa domain. Comparison analysis of driving and nested model results. Geophys Res 116:D15111. doi:10.1029/2010JD015068
Mitchell TD, Jones PD (2005) An improved method of constructing a database of monthly climate observations and associated high-resolution grids. Int $\mathrm{J}$ Climatol 25: 693-712

> Pal JS, Small EE, Eltahir EAB (2000) Simulation of regionalscale water and energy budgets: representation of subgrid cloud and precipitation processes within RegCM. J Geophys Res 105:576-594

Pal JS, Giorgi F, Bi XQ, Elguindi N and others (2007) Regional climate modeling for the developing world: the ICTP RegCM3 and RegCNET. Bull Am Meteorol Soc 88: 1395-1409

Randall DA, Wood RA, Bony S, Colman R and others (2007) Climate models and their evaluation. In: Solomon S, Qin D, Manning M, Chen Z and others (eds) Climate change 2007: the physical science basis. Contribution of Working Group I to the 4th Assessment Report of the Intergovernmental Panel on Climate Change. Cambridge University Press, Cambridge

Shi YF, Shen YP, Hu RJ (2002) Preliminary study on signal, impact and foreground of climatic shift from warm-dry to warm-humid in Northeast China. J Glaciol Geocry 24: 220-226 (in Chinese with English abstract)

Wang HJ (2001) The weakening of Asian monsoon circulation after the end of 1970's. Adv Atmos Sci 18:376-386

Xie PP, Yatagai A, Chen MY, Tadahiro H and others (2007) A gauge-based analysis of daily precipitation over East Asia. J Hydrometeorol 8:607-625

$\mathrm{Xu} \mathrm{CH}$, Shen XY, Xu Y (2007) An analysis of climate change in East Asia by using the IPCC AR4 simulations. Adv Clim Change Res 3:287-292 (in Chinese with English abstract)

> Xu Y, Gao XJ, Giorgi F (2009a) Regional variability of climate change hot-spot in East Asia. Adv Atmos Sci 26:783-792

$>$ Xu Y, Gao XJ, Shen Y, Xu CH and others (2009b) A daily temperature dataset over China and its application in validating a RCM simulation. Adv Atmos Sci 26:763-772

> Xu Y, Gao XJ, Giorgi F (2010) Upgrades to the REA method for producing probabilistic climate change predictions. Clim Res 41:61-81

Yu ET, Wang HJ, Sun JQ (2010) A quick report on a dynamical downscaling simulation over China using the nested model. Atmos Oceanic Sci Lett 3:325-329

Zhai PM, Zhang XB, Wan H, Pan XH (2005) Trends in total precipitation and frequency of daily precipitation extremes over China. J Clim 18:1096-1108

Zhang DF, Gao XJ, Ouyang LC (2008) Simulation of present climate over China by a regional climate model. J Trop Meteorol 14:19-23

> Zhou TJ, Li ZX (2002) Simulation of the East Asian summer monsoon by using a variable resolution atmospheric GCM. Clim Dyn 19:167-180

Zhou TJ, Qian YF (1995) The design and forecast verification of an one-way nested fine-mesh limited area numerical model. J Trop Meteorol 11:342-353 (in Chinese with English abstract)

Zhou TJ, Li LJ, Li HM, Bao Q (2008) Progress in climate change attribution and projection studies. Chinese $\mathrm{J}$ Atmos Sci 32:906-922 (in Chinese with English abstract)

> Zhou TJ, Gong DY, Li J, Li B (2009) Detecting and understanding the multi-decadal variability of the East Asian summer monsoon-recent progress and state of affairs. Meteorol Z (Berl) 18:455-467 